\title{
Effects of microalgal diets on larval growth and survival of Paphia malabarica chemnitz
}

\author{
Raghavan Gireesh \& Cherukara Purushothaman Gopinathan \\ Central Marine Fisheries Research Institute, Kochi, Kerala, India
}

Correspondence: R Gireesh, Central Marine Fisheries Research Institute, Ernakulam North PO, Kochi 682018, Kerala, India. 682018.

E-mail: girmsr@gmail.com

\begin{abstract}
The effects of food availability on the larval growth and survival of Paphia malabarica were studied in two experiments by feeding the larvae with six algal diets. Newly hatched larvae of $P$. malabarica were fed with six different marine microalgae species, singly and in a combination of two species. The best growth was with Isochrysis galbana and Nannochloropsis sali$n a$ as a single species of diet. The nutritional value of single-species diets was in the order of N. salina, I. galbana, Dicrateria inornata, Chaetoceros calcitrans, Tetraselmis gracilis and Dunaliella salina. Of the mixtures tested, $50 \%$ I. galbana $/ 50 \%$ N. salina supported growth and metamorphosis equivalent to those of the I. galbana control.
\end{abstract}

Keywords: Paphia malabarica, larvae, algal diets, growth, survival

\section{Introduction}

The yellow neck clam, Paphia malabarica, is an important clam resource in Ashtamudi estuary, south west of India, and emerging fishery of commercial importance (Appukuttan 1996). They are widely exploited for both meat as food and shell as raw material for industrial applications (Appukuttan, Aravindan, Yohannan \& Balasubramaniam 1999) and hence is an important income resource for local people. The species has great market demand in Japan and other European countries. Even though the species are widely distributed along the coastal and estuarine areas in Vietnam, China and Bangladesh, there is no report on clam culture using a standard protocol. With rapidly increasing demands, the natural stocks are overexploited. Overexploitation of under-sized clams and non-availability of seed are the major constraints for the culture of this species. Larval rearing of other cultivable clam species Meretrix meretrix (Narasimham, Muthiah, Gopinathan \& Gandhi 1988) and Anadora granosa (Muthiah, Narasimham, Gopinathan \& Sundararajan 1992) lead to seed availability and ranching in natural habitats. Larval rearing and sea ranching of seeds of P. malabarica species have been attempted on an experimental basis to aid stock restoration efforts. However, little information is available on the nutritional requirements of $P$. $m a-$ labarica larvae and no previous study has been reported on the relative food values of different species of microalgae for P. malabarica larvae.

Most marine invertebrate larvae develop for a certain time in the plankton stage before metamorphosis. The development of $P$. malabarica larvae is similar to other bivalve species. The larvae experience zygotes, trochophore, D-larvae and Prodissoconch II stage. During this period of time, planktotrophic larvae acquire their food from seawater to obtain energy for growth and development. In commercial shellfish hatcheries, the diets for bivalve larvae rearing are mainly cultured live microalgae (Laing 1987). Hence, optimizing the species composition of microalgal diets for a particular species should be of critical importance.

Crisp, Yule and White (1985) stated that the results from their studies on bivalve larvae support the inconsistency that food levels in the aquatic environment appear to be insufficient to support optimal growth, or in fact any growth at all. Larvae generally have greater metabolic demands than spat due to high mass-specific metabolic rates (Widdows 1991). Based on laboratory experiments, the amount of 
phytoplankton in the ocean is rarely present at concentrations necessary to sustain maximum larval growth. Hence, it is necessary to study how bivalve larvae acquire food from seawater or endure the absence of diets. The relationships among egg size, energy content and larval life-history strategies have also been studied extensively (Hart 1995; Levitan 2000; Moran \& Manahan 2004). Considerable attention has also been focused on the physiological capacity of planktotrophic larval forms of marine invertebrates to resist starvation. Such larval forms often develop from small eggs with a low-energy content (Vance 1973) and are presumed to be highly dependent on exogenous foods soon after the first feeding stage is reached (Anger 1987; Starr, Himmelman \& Herriault 1990; His \& Seaman 1992; Bochenek, Klinck, Powell \& Hofmann 2001). These models use the assumption that before the onset of feeding, larvae behave as closed metabolic systems that are predominantly fuelled by endogenous energy reserves rather than energetic inputs from the environment (Moran \& Manahan 2004). One of the valuable methods to evaluate the differences in food value is to estimate the relative growth efficiency of the larvae fed with various diets (Laing \& Millican 1986). The objectives of the present study were to find the optimal algal diets in larval rearing and its effects on growth, survival and metamorphosis of $P$. malabarica larvae.

\section{Materials and methods}

\section{Brood stock and larvae collection}

The experiment was carried out in December 2002 at the Tuticorin Research Centre of Central Marine Fisheries Research Institute, India. The adult clams were collected from Ashtamudi estuary (Latitude $8^{\circ} 45^{\prime} \mathrm{N}$; Longitude $78^{\circ} 28^{\prime} \mathrm{E}$ ), where P. malabarica was one of the major bivalve species. Brood stock clams were conditioned at $24-25{ }^{\circ} \mathrm{C}$ for about 20 days to speed up their gonad development. The clams were dried in the dark for 4-6 h, and then shifted to a higher temperature filtered seawater $(0.45 \mu \mathrm{m}$, $28-30{ }^{\circ} \mathrm{C}$ ) to induce spawning. About $4-6 \mathrm{~h}$ after being induced, the clams began to spawn. The zygotes were cultured in $0.45 \mu \mathrm{m}$ filtered seawater at a density of 5-7 zygotes $\mathrm{mL}^{-1}$. When the zygotes developed to the D-larvae stage (about $24 \mathrm{~h}$ after fertilization at $26-27^{\circ} \mathrm{C}$ ), the larvae were collected using a $100 \mu \mathrm{m}$ mesh, and transferred to natural filtered seawater $(0.45 \mu \mathrm{m})$.
The microalgae used in this experiment were obtained from CMFRI, and batch cultured using a scale-up from 5 to $20 \mathrm{~L}$ glass carboys. Microalgae were grown at $22-26^{\circ} \mathrm{C}$ in sterilized media. The photoperiod was 24:0 (light/dark), and illumination was provided by two daylight $(40 \mathrm{~W})$ fluorescent tubes. Seawater (salinity $=30.0 \pm 1.0$ ) was $0.45 \mu \mathrm{m}$ filtered, and UV treated. Continuous aeration was provided to enhance growth and prevent the algae from settling. The algae were harvested at the exponential phase for feeding. Replicate three to six culture carboys of each species were used throughout the experiment.

\section{Experiment}

Effects of different algae diets on the growth and metamorphosis of larvae

The larvae collected were transferred into $4 \mathrm{~L}$ natural filtered seawater $(0.45 \mu \mathrm{m})$. Seawater salinity was $30.0 \pm 1.0$ and the temperature ranged from 22.0 to $24.5^{\circ} \mathrm{C}$. The seawater was renewed every alternate day and the number of larvae in each beaker was counted by sampling. Six microalgae species (Isochrysis galbana, Nannochloropsis salina, Dicrateria inornata, Tetraselmis gracilis, Chaetoceros calcitrans and Dunaliella salina) and three mixed diets (50\% I. galba$n a / 50 \%$ N. salina, $50 \%$ N. salina $/ 50 \%$ D. inornata and $50 \%$ N. salina $/ 50 \%$ T. gracilis) were selected to determine the effects of different algae diets. The algae were harvested at the exponential phase for feeding. In order to control the final concentration of microalgae in the experimental beaker, the feeding quantity was determined by measuring the original concentration of different microalgae diets exactly.

From day 0 to day 3, all diets were fed at a concen-

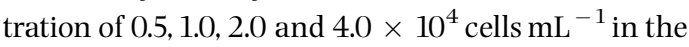
water media of the beaker; after day 3 , the concentration of $4.0 \times 10^{4}$ cells $\mathrm{mL}^{-1}$ was maintained until the end of the test. For the mixture diet experiments, two microalgae diets were adjusted to the same concentration and then mixed with half-volume of each diet before they were used to feed the larvae. There were equal cell numbers in the experimental beaker. Each treatment included three replicates with the same larvae concentration (about 6 larvae $\mathrm{mL}^{-1}$ ). Survival were measured as the percentage of initial $(n=100)$ surviving each observation interval. Antero-posterior shell length and dorso-ventral shell height was measured for 20 randomly sampled larvae from each replicate using an ocular 
micrometer. The experiment was carried out for 10 days. Relative growth was calculated using the formula of Walne (1963)

$$
K=\left(\ln L_{2}-\ln L_{1}\right) / t
$$

where $L_{1}, L_{2}$ are the lengths at the beginning and the end of the experiment, respectively, and $t$ is the duration of the experiment in days.

\section{Statistical analysis}

All data were analysed by ANOVA, and significant differences between treatments means were determined by the Tukey test using spss software. Survival data were arcsin transformed before statistical analysis. The significance level for all analyses was set at $P<0.05$. Data are presented as mean \pm SE.

\section{Results}

Larvae from different beakers were examined and their shell length and width were recorded. The results showed that shell length and width presented as a positive correlation, $y=1.0332 x+15.508 \mu \mathrm{m}$, $r^{2}=0.9205$ (Fig. 1). This means that larvae developed normally and length could be used as a suitable indicator of growth. From observations and statistical analysis, it was found that larvae crawled using the developed foot at a shell length of $220-270 \mu \mathrm{m}$, which provided a method to estimate the metamorphosis rate.

The growth of P. malabarica larvae fed various diets after 10 days is shown in Fig. 2. Early foot development and spat settlement was observed in larvae fed with $N$. salina and the three mixed diets of the same species on day 7. Larvae with other test diets showed

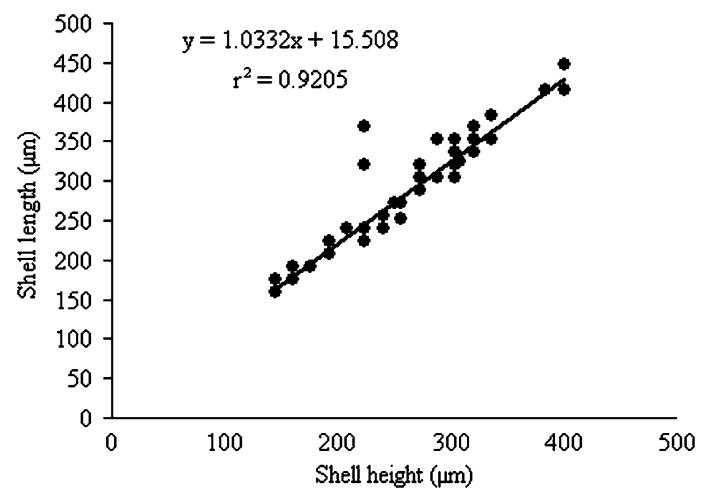

Figure 1 Relationship between larvae shell length and width.

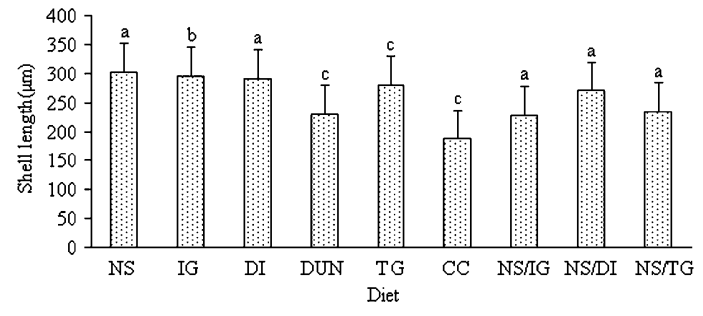

Figure 2 Mean shell length of Paphia malabarica larvae fed various single or mixed diets over a 10-day period. Mixed diets are at an equal concentration $(50 \% \mathrm{v} / \mathrm{v})$. Means with the same superscript are not significantly different $(P>0.05)$.

Table 1 Relative growth $(K)$ until day 10 and foot developed time of Paphia malabarica larvae fed various algal diets

\begin{tabular}{lll}
\hline Diets & $\boldsymbol{K}$ & Foot development \\
\hline $\mathrm{NS}$ & $2.252 \pm 0.156^{\mathrm{a}}$ & Day 7 \\
IG & $2.287 \pm 0.087^{\mathrm{b}}$ & Day 9 \\
$\mathrm{DI}$ & $2.255 \pm 0.070^{\mathrm{a}}$ & Day 7 \\
DS & $2.286 \pm 0.059^{\mathrm{c}}$ & Day 10 \\
TG & $2.321 \pm 0.074^{\mathrm{c}}$ & Day 10 \\
$\mathrm{CC}$ & $2.064 \pm 0.061^{\mathrm{c}}$ & Day 10 \\
NS/IG & $2.219 \pm 0.093^{\mathrm{a}}$ & Day 7 \\
NS/DI & $2.223 \pm 0.064^{\mathrm{a}}$ & Day 7 \\
NS/TG & $2.162 \pm 0.044^{\mathrm{a}}$ & Day 7 \\
\hline
\end{tabular}

The data were means of \pm SD of replicates. $K$, relative growth $(\mu \mathrm{m})$; NS, Nannochloropsis salina; IG, Isochrysis galbana; DI, Dicrateria inornata; DS, Dunaliella salina; TG, Tetraselmis gracilis; CC, Chaetoceros calcitrans. Means with the same superscript letters are not significantly different $(P>0.05)$.

foot development and spat settlement on day 9 or 10 (Table 1). No significant differences were detected in terms of shell length among larvae fed different algal diets. However, a high survival and relative growth rate $(31.5 \%$ and $2.252 \%)$ was observed in larvae fed with N. salina than other mono diets (Fig. 3 and Table 1). The mixed diet of the same species with I. galbana also showed a similar performance in relative growth and survival $(2.219 \%$ and $22.7 \%)$. Larvae fed with I. galbana showed relative growth (2.287), but the survival was low (22.4\%). Larvae fed C. calcitrans had the lowest growth rate (2.064) and larvae fed D. salina, showed the low survival (1.4\%).

\section{Discussion}

Successful metamorphosis in marine invertebrates including bivalves depends on the energy reserves 


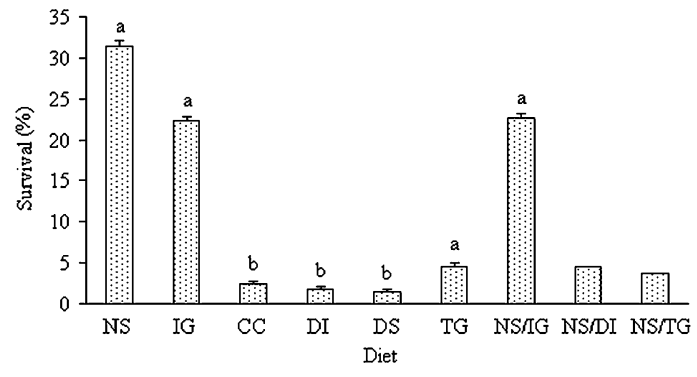

Figure 3 Survival of Paphia malabarica larvae fed six single or mixed diets after 10 days of subsequent feeding. Means with the same superscript are not significantly different $(P>0.05)$.

stored up during two developmental stages (Labarta, Fernandez-Reiriz \& Perez-Camacho 1999). The first, which corresponds to embryonic development, is mainly governed by the endogenous reserves that the parents provided in the egg (Bayne 1973). There is a detailed description of the transition process in marine bivalve from the trocophore larva stage to the veliger larva stage. The second stage, in which stored reserves are essential, is a process that takes place before metamorphosis and depends on the food value of diets that are provided to promote larval growth (Whyte, Bourne \& Hodgson 1989; Whyte, Bourne \& Ginther 1990). The velum disintegrates with the onset of metamorphosis, which limits movement and inhibits feeding. The use of endogenous reserves during metamorphosis reflects the inability of bivalves to capture food particles during the metamorphosis period when bivalve larvae replace the velum with the juvenile and adult feeding organ, branchia. The processes involved have been described previously (Cranfield 1973).

In the present experiment, no significant difference was detected in terms of shell length among different algal treatments in the initial days. This suggested that during this period, larval growth mainly depends on the energy reserve in the embryo. After attaining the 'D' shape, larvae began to ingest algal food from the ambient environment and showed a difference in growth among the different treatments. During the feeding trials, the best growth (increase in shell length) and survival of P. malabarica larvae was with the $N$. salina diet. Larvae fed the mixed diets of N. salina with I. galbana also showed good performance than I. galbana alone. The larvae performed moderately well when fed Dicrateria iornata or T. gracilis and poorly with D. salina or C. calcitrans. As the size of algae is also an important factor during feeding, the preference of low-size $N$. salina $(2 \mu \mathrm{m})$ could be considered to be an appropriate food for P. malabarica larvae, as they attained their maximum growth and survival with this alga. This result indicates that a combination of $N$. salina with any other flagellates influences larval survival and better growth in the early stages before settlement. A number of previous studies have shown that when fed I. galbana and any one of Dunaliella sp., Phaeodactylum tricornutum and $P$. subcordiformis, the larvae preferably selected I. galbana and the intestines of the larvae were filled with mainly I. galbana. Here also the size plays a critical role, where I. galbana (7$8 \mu \mathrm{m})$ is lower than these species. In the present case, N. salina remains preferable to I. galbana in terms of size. This showed that $P$. malabarica larvae showed selected feeding of algal diets. This feeding behaviour may also be related to essential nutrients and the form differences in the algae, as the cell of N. salina is round and smaller in volume than the other diets. The selective feeding of $P$. malabarica larvae of various algal diets may be another factor that influences their growth and survival. These results also illustrate the importance of an acceptable feeding protocol for the most efficient utilization of the diet and to obtain the best growth. It clearly shows the importance of providing $P$. malabarica larvae with the appropriate algal diet. With $N$. salina alone or mixed with other algae, the larvae will grow faster and have a higher quality. Also, because the food is utilized more efficiently, the algal production costs can be kept to a minimum (Laing \& Millican 1986).

\section{Acknowledgments}

The authors are grateful to the Director, CMFRI, for encouragement and the facilities provided. They sincerely thank Dr K. K. Appukuttan, Head, Molluscan Division, and Dr P. Muthiah for their valuable suggestions. The first author gratefully acknowledges the Department of Ocean Development for the award of Research Assistantship.

\section{References}

Anger K. (1987) The DO threshold: a critical point in the larval development of decapod crustaceans. Journal of Experimental Marine Biology and Ecology 108, 15-30.

Appukuttan K.K. (1996) Short neck clam fishery in Ashtamudi estuary. Sea Food Export Journal 27, 17-24. Appukuttan K.K., Aravindan C.M., Yohannan T.M. \& Balasubramaniam N.K. (1999) Population dynamics of an 
exploited stock of the clam, P. malabarica of Ashtamudi Estuary (South India). In: The Fourth Indian Fisheries Forum Proceedings (ed. by M.J. Mohan, N.R. Menon \& N.V. Nair), pp. 31-34. Asian Fisheries Society, Indian Branch, Mangalore, India.

Bayne B.L. (1973) Aspects of the metabolism of Mytilus edulis during starvation. Netherlands Journal of Sea Research 7 , 399-441.

Bochenek E.A., Klinck J.M., Powell E.N. \& Hofmann E.E. (2001) A biochemically based model of the growth and development of Crassostrea gigas larvae. Journal of Shellfish Research 20, 243-265.

Cranfield H.J. (1973) Observations on the behaviour of the pediveliger of Ostrea edulis during attachment and cementing. Marine Biology 22, 203-209.

Crisp D.J., Yule A.B. \& White K.N. (1985) Feeding by oyster larvae - the functional - response, energy budget and a comparison with mussel larvae. Journal of the Marine Biological Association of the United Kingdom 65, 759-783.

Hart M.W. (1995) What are the costs of small egg size for a marine invertebrate with feeding planktonic larvae? American Naturalist 146, 415-426.

His E. \& Seaman M.N.L. (1992) Effects of temporary starvation on the survival, and on subsequent feeding and growth, of oyster (Crassostrea gigas) larvae. Marine Biology 114, 277-279.

Labarta U., Fernandez-Reiriz M.J. \& Perez-Camacho A. (1999) Energy, biochemical substrates and growth in the larval development, metamorphosis and postlarvae of Ostrea edulis. Journal of Experimental Marine Biology and Ecology 238, 225-242.

Laing I. (1987) The use of artificial diets in rearing bivalve spat. Aquaculture 65, 243-249.

Laing I. \& Millican P.F. (1986) Relative growth and growth efficiency of Ostrea edulis L. spat fed various algal diets. Aquaculture 54, 245-262.
Levitan D.R. (2000) Optimal egg size in marine invertebrates: theory and phylogenetic analysis of the critical relationship between egg size and development time in echinoids. American Naturalist 156, 175-192.

Moran A.L. \& Manahan D.T. (2004) Physiological recovery from prolonged starvation in larvae of the Pacific oyster Crassostrea gigas. Journal of Experimental Marine Biology and Ecology 306, 17-36.

Muthiah P., Narasimham K.A., Gopinathan C.P. \& Sundararajan D. (1992) Larval rearing, spat production and juvenile growth of the blood clam Anadora granosa. Journal of Marine Biological Association of India 34, 138-143.

Narasimham K.A., Muthiah P., Gopinathan C.P. \& Gandhi A.D. (1988) Larval rearing and spat production of the great clam, Meretrix meretrix (Linnaeus). Indian Journal of Fisheries 35, 107-112.

Starr M., Himmelman J.H. \& Herriault J.C. (1990) Direct coupling of marine invertebrate spawning with phytoplankton blooms. Science 247, 1070-1074.

Vance R.R. (1973) On reproductive strategies in marine benthic invertebrates. American Naturalist 107, 339-352.

Walne P.R. (1963) Observations on the food value of seven species of algae to the larvae of Ostrea edulis. Journal of the Marine Biological Association of the United Kingdom 43, $767-784$.

Whyte J.N.C., Bourne N. \& Ginther N.G. (1990) Biochemical and energy changes during embryogenesis in the rock scallop Crassadoma gigantea. Marine Biology 106, 239-244.

Whyte N.J.C., Bourne N. \& Hodgson C.A. (1989) Influence of algal diets on biochemical composition and energy reserves in Patinopecten yessoensis (Jay) larvae. Aquaculture 78, 333-347.

Widdows J. (1991) Physiological ecology of mussel larvae. Aquaculture 94, 147-163. 